\title{
Serviço Social e o trabalho com famílias: renovação ou conservadorismo?
}

\author{
Social Work and working with families: renovation or \\ conservantism?
}

Claudio Henrique Miranda Horst* Regina Célia Tamaso Mioto**

\begin{abstract}
Resumo - O objetivo do presente texto é apontar elementos que caracterizam o trabalho com famílias na história da profissão buscando identificar os desafios presentes colocados para uma atuação que historicamente muda de forma, preservando, no entanto, compromissos sociopolíticos com o conservadorismo. O artigo aborda a necessidade do aprofundamento crítico no debate sobre famílias, o trabalho com estas no interior da profissão, assim como a necessária articulação, para além dos marcos normativos das políticas, com os elementos que constituem o projeto ético político.
\end{abstract}

Palavras-chave: Serviço Social; Famílias; Atuação Profissional.

\begin{abstract}
The objective of the present article is to analyze the work with families throughout history of this profession, aiming to identify the present challenges set to a performance that historically "changes shape, preserving, however, sociopolitical commitments to conservantism". The article points to the need to deepen the debate regarding families and the work with those in the profession, as well as the necessary articulation, beyond the policies legal boundaries, with elements which constitute our ethical-political project.
\end{abstract}

Keywords: Social work; Families; Professional Performance.

\footnotetext{
* Assistente Social, Doutorando em Serviço Social pela Universidade Federal de Santa Catarina. Mestre em Política Social pela Universidade Federal do Espírito Santo. Correspondência: Rua Antônio Francisco da Silveira, número 373, Casa, Bairro Pantanal, Florianópolis - Santa Catarina. CEP: 88040-160. Email: $<$ claudiovasques1@hotmail.com>.

** Assistente social. Doutora em Saúde Mental (Unicamp). Professora do Programa de Pós-Graduação em Serviço Social da Universidade Federal de Santa Catarina. Bolsista de Produtividade em Pesquisa/CNPq. Correspondência: Universidade Federal de Santa Catarina, Campus Reitor João David Ferreira Lima, s/n - Trindade, Florianópolis SC. CEP: 88040-900. Email: <regina.mioto@gmail.com>.
} 


\title{
1. Introdução: qualquer caminho serve?
}

\author{
Alice perguntou: Pode me dizer qual o caminho que eu devo tomar? \\ Isso depende muito do lugar para onde você quer ir - disse o Gato. \\ Eu não sei para onde ir! - disse Alice. \\ Se você não sabe para onde ir, qualquer caminho serve. \\ (Alice no País das Maravilhas - Lewis Carroll).
}

O objetivo do presente texto é apontar elementos que caracterizam o trabalho com famílias na história da profissão buscando identificar os desafios presentes na atuação junto à famílias da classe trabalhadora num país dependente. Nosso pressuposto é que, na atual fase do capitalismo com a predominância de sua forma mais fetichizada, o capital fictício -, há o reordenamento das políticas sociais, o que vem demandando um perfil profissional "competente no gerenciamento e monitoramento da pobreza e, portanto, funcional a um Estado assistencial e penal" (RODRIGUES, 2012, p. 52), ou seja, na contramão do Projeto Ético Político profissional. Dessa forma, observa-se o forte retorno do conservadorismo, principalmente no que diz respeito à atuação junto a questões que não avançaram no amadurecimento teórico no interior da profissão, a exemplo o trabalho com famílias.

Trata-se de investigar, a partir de uma reflexão entre o passado e o presente profissional, como a atuação "muda de forma, preservando, no entanto, compromissos sociopolíticos com o conservadorismo" (IAMAMOTO, 2013, p.23). Assim, o que objetivamos é discutir o papel do trabalho com famílias num cenário de "retomadas de perspectivas que na renovação profissional não ambicionavam romper com o tradicionalismo" (RODRIGUES, 2012, p. 52).

O trabalho está organizado em três momentos. No primeiro, situase a contraditória relação entre a política social no capitalismo dependente e a centralidade das famílias da classe trabalhadora que constitui o chão do trabalho com famílias. No segundo momento, debate-se a questão da família no Serviço Social, tentando pontuar as bases que historicamente pautam o trabalho com famílias, bem como aquelas que se alinham ao projeto ético político da profissão. E por fim, apontaremos algumas reflexões sobre a necessidade histórica de uma atuação junto a famílias atrelada ao Projeto Ético Político profissional.

Com inspiração no diálogo de Alice no país das Maravilhas, pretendemos demonstrar que, "se não sabemos para onde queremos ir", ou seja, se desconhecemos a intencionalidade e o compromisso da nossa atuação junto a famílias da classe trabalhadora, continuaremos fadados a um trabalho que culpabiliza essas famílias, classificando-as "desestruturadas", e, dessa forma reproduz uma prática profissional que confronta o horizonte profissional aberto desde a década de 1970. 


\section{Política social e família: confluência perversa!}

Num cenário de aprofundamento da crise estrutural do sistema do capital, conforme aponta Mészáros (2002), não temos dúvidas do não lugar reservado à política social dentro desse sistema, uma vez que, conforme denuncia Marques (2015), as políticas sociais têm se revelado um obstáculo para os interesses do capital em geral e do capital financeiro em particular.

O único interesse que esse tipo de capital tem em relação às políticas sociais é na transformação dos sistemas públicos de aposentadoria (de repartição) em sistemas privados, de capitalização, como forma de amealhar mais recursos para suas atividades especulativas. [...] O único nível de políticas sociais admitido, organizado e financiado pelo Estado, é aquele dirigido à população muito pobre (MARQUES, 2015, p.18).

Fruto da correlação de forças estabelecidas entre o capital e os trabalhadores, políticas sociais organizadas e financiadas pelo Estado numa perspectiva de universalização situam-se num momento do padrão de acumulação que se esgotou, experiência essa, característica de países europeus. Portanto, se falamos de experiências - como o Welfare State - que não são mais possíveis nos países centrais dada a necessidade de aumento da taxa de lucro, tal aposta nem sequer se vislumbra no horizonte de países dependentes.

No que tange às determinações da política social na América Latina, estas devem partir da compreensão de uma especificidade latinoamericana, como apontam Paiva e Ouriques (2006).

A política social como fundamental para a regulação política no sistema capitalista apresenta, na América Latina, características específicas, determinadas pela sua formação social nos marcos da dependência, que, nesse contexto, "desnudam os limites das soluções reformistas e pseudo-integradoras, nos moldes do que hoje se atribui às mal denominadas políticas de "inclusão social" (PAIVA; OURIQUES, 2006, p.171). Essa forma de modelo econômico - periférico e dependente - expõe a realidade do país e da região.

A classe trabalhadora na América Latina (que seria o sujeito de direitos num país central) é composta por um expressivo contingente de trabalhadores informais e de desempregados, para os quais não há sequer vínculo salarial formal nem muito menos acesso à proteção social, decorrentes da sociedade salarial. Enfim, para a grande maioria da população, pobreza e miséria vêm acompanhadas da omissão do Estado, expressa, sobretudo, na ausência de políticas sociais, ou, na maioria das vezes, num tipo determinado de política social, cujo horizonte não pode ser pretensioso em termos sociais e políticos e no qual todo radicalismo deve ser combatido, seja em termos da composição do gasto social seja em função da dimensão emancipadora que elas poderiam conter (PAIVA; OURIQ̉UES, 2006, p. 172). 


\section{ReVistg all paltg}

\} SERVIÇO SOCIAL E O TRABALHO COM FAMÍLIAS - HORST, C. H. M.; MIOTO, R. C. T. \}

DOI: $10.12957 /$ REP.2017.32749

Mesmo com a tentativa histórica de construção de um Estado para o social - presente na história da proteção social estatal brasileira a partir da Constituição de 1988 -, não se conseguiu alcançar a universalidade desejada. Em vez disso, aprofundou-se o caminho para uma política social pensada de modo residual, sustentada pelas orientações neoliberais. Ao tratarmos da experiência do Estado brasileiro, observa-se que este sempre se ausentou e contou com "[...] alternativas privatistas que envolvem a família, as organizações sociais e a comunidade em geral" (YAZBEK, 2016, p. 09) no provimento da proteção social.

Como afirma Campos (2015), a atual posição da família na Política Social não é uma novidade e não pode ser analisada apenas como consequência da política neoliberal em ascensão a partir dos anos de 1990. Ao contrário, a família sempre foi instância central na configuração da proteção brasileira e referência na estruturação das políticas setoriais, como saúde, educação, previdência. Para Goldani (2005), as políticas referidas às famílias são aquelas que através de um conjunto de normativas e instrumentos buscam fortalecer as suas funções sociais tendo em conta sua estrutura, suas características ou a demanda de seus membros. Tal centralidade da família, tanto como principal instância de provisão de bem-estar como de referência para a política social, define o caráter familista das sociedades latino-americanas. Familismo entendido como um padrão de interrelação reinante na sociedade, em que no nível macrossocial, na organização dos sistemas de proteção social, a família é colocada como instituição provedora central de bem-estar. No nível micro social, uma rede de mulheres (mães, avós, vizinhas...) respondem pelo trabalho familiar, especialmente pelo cuidado dos dependentes (BATTHYÁNY, 2015). No Brasil vem sendo considerado um padrão cultural e político secular que tem se expressado no campo da legislação (solidariedade obrigatória) e na configuração da política social (MIOTO ET AL., 2015; COSTA; GOLDANI, 2015).

A manutenção desse padrão familista torna-se essencialmente útil num momento em que, de acordo com Mota (2017), se exaure a estratégia de conciliação de classes que abrangeu os governos do PT na presidência do país e permitiu a ampliação de serviços de infraestrutura e criação de políticas compensatórias de alívio à pobreza. Ao ampliarem-se no pós-golpe de 2016 os novos mecanismos de exploração da força de trabalho, de supressão de direitos sociais e especialmente de privatização e/ou mercantilização da educação, da saúde, da previdência e, consequentemente, dos serviços públicos, nos parece que a família assume lugar ainda mais estratégico no processamento desses mecanismos, especialmente em relação à privatização da provisão de bem-estar.

O que estamos tentando demonstrar é a contraditória relação entre política social no capitalismo dependente, agravada pela crise atual, e a centralidade nas famílias da classe trabalhadora. Como sinaliza o título que abre o presente tópico, essa confluência perversa para as famílias - mas 


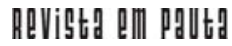

\} SERVIÇO SOCIAL E O TRABALHO COM FAMÍLIAS - HORST, C. H. M.; MIOTO, R. C. T. \}

DOI: $10.12957 /$ REP.2017.32749

nada para o capital - sempre acarretará sobrecarga e culpabilização das famílias e, principalmente, das mulheres. Silveira Junior (2016), ao demonstrar as tendências político pedagógicas postas aos trabalhadores do SUAS, chamou atenção para a característica da atuação com famílias.

Efetivamente, ela tem seu fulcro conduzido para o enfrentamento do 'risco e vulnerabilidade social', o que se expressa na fixação das suas prioridades em termos do 'desenvolvimento de capacidades' dos indivíduos e famílias atendidos. Mas, nessa esteira, ocorre uma indução de metodologias de trabalho socioassistencial com acentuado teor individualizador e marcado peso psicologizante. A individualização se expressa na proposição de metodologias de trabalho social centradas na mudança de projetos individuais (ou familiares) para a superação da condição de pobreza. A psicologização é conformada, não somente por uma moralização estrito sensu da pobreza, donde redundaram, no passado, inclusive terapias de ajustamento, mas pela promessa de sua suplantação por meio da escolarização, profissionalização e/ou assimilação de aptidões empreendedoras, que capacitariam para a luta individual por ascensão social na concorrência do mercado. O que oportunizaria a 'emancipação' (ou a 'autonomia') dos usuários da assistência social e suas famílias. Aqui, a hipoteca permanece na redefinição de características pessoais dos indivíduos, na mudança subjetiva, representada no alcance de determinados conteúdos culturais e atitudes sociais que representariam a 'porta de saída' da sua condição social (SILVEIRA JUNIOR, 2016, p. 65).

Na contramão dessa lógica, estamos apostando na política social como "motor de uma nova institucionalidade democrática, contribuindo para uma dinâmica de transformação social que mobiliza e organiza as massas a partir de seus interesses mais fortes" (PAIVA; ROCHA; CARRARO, 2010, p. 168). E é nesse sentido que o trabalho com famílias pode fazer toda diferença se direcionado em consonância com o Projeto Ético Político profissional.

Podemos, portanto, afirmar que a relação entre política social e famílias, dependendo da compreensão que se tem de ambas as instituições, constitui uma confluência perversa. Isso porque, se apostarmos na política social como espaço de disputa junto a famílias, essa relação pode ser de potência. No entanto, o que se legitima é uma relação perversa - já estabelecida a priori - na qual a política social, longe da possibilidade de desvendamento da realidade como forma de luta, tenderá sempre a jogar para cima das famílias responsabilidades que elas, dadas as suas condições objetivas de vida, não são capazes de assumir. Entender essas contradições a partir da atuação profissional e as opções que temos feito ou não, historicamente, junto ao trabalho com famílias é a tarefa necessária. 


\section{Famílias e Serviço Social: a necessidade histórica do rompimento com o conservadorismo}

A partir do século XX, a consolidação do modo de produção capitalista no Brasil, por meio do processo de industrialização, exigiu do Estado uma nova configuração, especialmente, para responder às questões decorrentes dos conflitos entre empresários e operariado e às expectativas de se construir uma "nação moderna". Nesse movimento, a família foi alçada a uma condição estratégica, tanto para desativar os conflitos no âmbito da produção como para consolidar relações sociais pautadas nos ideais de modernidade. No contexto dos anos de 1930, surgiram as primeiras iniciativas do Estado brasileiro na conformação de políticas públicas destinadas às famílias, inspiradas, de acordo com Neder (1994), no autoritarismo nazi-facista, que tinha como paradigma o ideal de "família regular" e "saudável", paradigma esse construído pelas formulações gestadas especialmente no campo médico, jurídico e urbanístico (NEDER, 1994). Essas formulações forneceram o suporte técnico e teórico, abraçado pela Igreja Católica, para a implementação de políticas públicas nessa área e para a colocação no mercado de trabalho de um conjunto de novos profissionais, dentre eles, os assistentes sociais.

Incorporado por esses princípios, o Serviço Social será determinado por uma ação de soerguimento moral da família operária, atuando principalmente com mulheres e crianças. A atuação aqui não se caracteriza apenas por exercer a caridade, mas se configura principalmente como forma de intervenção ideológica na vida das famílias da classe trabalhadora. Como demonstra lamamoto, os efeitos dessa atuação são essencialmente políticos: "o enquadramento dos trabalhadores nas relações sociais vigentes, reforçando a mútua colaboração entre capital e trabalho" (IAMAMOTO, 2013, p. 23).

Diferenciado da caridade tradicional, vista como mera reprodução da pobreza, o Serviço Social propõe uma ação educativa entre a família trabalhadora, numa linha não apenas curativa, mas preventiva dos problemas sociais. Distingue-se também da assistência pública, que, desconhecendo a singularidade e particularidade dos indivíduos, produz respostas não diferenciadas aos 'problemas sociais'. [...] Desconhecendo o caráter de classe dos antagonismos sociais, os efeitos desses antagonismos são considerados motivos relevantes para um tratamento socioeducativo da 'clientela', tratamento esse de cunho doutrinário e moralizador, amplamente haurido no senso comum da classe de origem desses profissionais $^{1}$ (IAMAMOTO, 2013, p. 23).

\footnotetext{
"O Serviço Social emerge como uma atividade com bases mais doutrinárias que cientificas, no bojo de um movimento de cunho reformista-conservador". Porém, como demonstra lamamoto (2013) os processos de secularização e de ampliação do suporte técnico-científico ocorreram sob a influência das Ciências Sociais nos marcos do pensamento conservador, especialmente com a vertente empiricista norte-americana.
} 


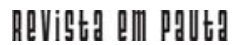

\} SERVIÇO SOCIAL E O TRABALHO COM FAMÍLIAS - HORST, C. H. M.; MIOTO, R. C. T. \}

DOI: $10.12957 /$ REP.2017.32749

Ao longo das décadas seguintes, o desenvolvimento das políticas sociais no campo estatal e o avanço do tecnicismo na profissão vão delinear um distanciamento cada vez maior entre as ações dos profissionais em relação às famílias e aquelas que continuaram sendo realizadas no campo da filantropia. Os profissionais passaram a definir cada vez mais suas ações a partir dos postulados metodológicos do Serviço Social de Caso, do Serviço Social de Grupo e do Serviço Social de Comunidade, mantendo, porém, a mesma lógica de atendimento às demandas do capital, por intermédio de um Estado interventor.

Durante todo esse período o trabalho com famílias no Serviço Social tinha como inspiração os caminhos abertos por Mary Richmond - Serviço Social de Caso - que através de seus relatos de casos apontava que as ações dos assistentes sociais deveriam incidir na higiene (pessoal e doméstica), na estrutura habitacional, respeito a propriedade, condutas sociais e familiares, retomada de laços familiares, ajuda na aquisição de hábitos e nas situações de "crises" associadas, em geral, aos grupos familiares (RICHMOND, 1977). Nos anos de 1950 e 1960 o CBCISS (Centro Brasileiro de Cooperação e Intercâmbio de Serviços Sociais) ${ }^{2}$, através de sua revista, publicou inúmeros textos relacionados à família, muitos de autores norte-americanos traduzidos para o português. Neles se divulgava e se fortalecia uma intervenção profissional pautada na perspectiva estrutural funcionalista de família.

Posteriormente, nesse viés funcional-estruturalista, especialmente a partir dos anos de 1970, pode ser observado a influência da teoria sistêmica nas práticas com famílias. Nos anos de 1980, encontra-se uma produção bibliográfica significativa sob essa ótica que acabou desembocando no desenvolvimento do denominado Serviço Social Clínico. A teoria sistêmica, através das terapias familiares, ancora grande parte da produção de conhecimento da segunda metade do século XX sobre processos de intervenção nas famílias. Foi desenvolvida na área da saúde mental, com a participação de diferentes profissionais (psiquiatras, psicólogos, assistentes sociais, enfermeiros) vinculados à teoria sistêmica e à psicanálise. Essa farta produção, que explica as dificuldades apresentadas pelos indivíduos a partir da estrutura e dinâmica familiares e informa acerca de procedimentos para efetuar mudanças, passou a ganhar primazia no campo interventivo. Tanto que se adentra na configuração do Trabalho Social com Famílias no SUAS, em plenos anos 2000, e ainda se faz presente num número expressivo de capacitações direcionadas aos profissionais, sejam realizadas pela iniciativa privada, sejam patrocinadas pelos gestores municipais do SUAS. Ela aparece e se consolida pela sua lógica explicativa dos "problemas familiares" e pela apresentação de formas "eficazes" de responder às demandas postas. Ou seja, traz respostas operativas ao cotidiano profissional. Respostas reclamadas pela categoria profissional desde os anos de 1970 e 1980 quando a profissão

${ }^{2}$ Até 1966 denominado de Centro Brasileiro de Cooperação e Intercâmbio de Serviço Social. 


\section{ReVistg all paltg}

\} SERVIÇO SOCIAL E O TRABALHO COM FAMÍLIAS - HORST, C. H. M.; MIOTO, R. C. T. \}

DOI: $10.12957 /$ REP.2017.32749

começa a se repensar sobre novas bases, deslocando o seu debate do eixo do "metodologismo", até então reinante, para o debate das relações sociais nos marcos do capitalismo, e abrir caminho para a construção do projeto ético-político do Serviço Social.

O deslocamento desse eixo se iniciou no final da década de 1960 com profissionais comprometidos com a realidade latino-americana e engajados num projeto político de transformação das condições estruturais da sociedade brasileira. Empreenderam um grande esforço para a construção de um marco teórico-metodológico para o Serviço Social, à luz de um posicionamento materialista-dialético, que pudesse responder às questões postas pela realidade latino-americana (IAMAMOTO, 2013).

Nesse processo, lamamoto e Carvalho (1982) buscaram reconstruir o objeto de estudo do Serviço Social, redefinindo-o como as expressões da questão social, ao mesmo tempo em que situam a profissão como "um dos elementos que participa da reprodução das relações de classes e do relacionamento contraditório entre elas", compreendendo-a como uma "profissão historicamente situada, configurada como um tipo de especialização do trabalho coletivo dentro da divisão social do trabalho peculiar à sociedade industrial" (IAMAMOTO; CARVALHO, 1982, p.71). A partir dessa concepção, firmaram o Serviço Social como instituição componente da sociedade; é esta que reproduz interesses em oposição, os quais estão em constante tensionamento. Portanto,

A partir dessa compreensão é que se estabelece uma estratégia profissional e política, para fortalecer as metas do capital ou do trabalho, mas não se pode excluí-las do contexto da prática profissional, visto que as classes só existem inter-relacionadas. É isto, inclusive, que viabiliza a possibilidade de o profissional colocar-se no horizonte dos interesses das classes trabalhadoras (IAMAMOTO; CARVALHO, 2014, p. 81).

Essa releitura proporcionou novas bases de sustentação da intervenção profissional dos assistentes sociais, pois permitiu compreender que, na sociedade capitalista, as ações profissionais estão profundamente condicionadas pelas relações entre as classes e que elas interferem na reprodução material e social da força de trabalho, tanto por meio das ações materiais como por meio das ações de cunho sociopolítico e ídeo-cultural. Ou seja, elas participam da reprodução das relações sociais que se faz pela reprodução de valores, de modos de vida e de práticas culturais e políticas (YAZBEK, 1999; SIMIONATTO, 1999).

De acordo com Mioto (2015), tal releitura possibilitou entender a intervenção profissional sob dois eixos. Um eixo é relacionado à interpretação das demandas colocadas aos assistentes sociais, a qual permite compreendê-las não mais como problemas individuais ou familiares, mas como expressões de necessidades humanas básicas não satisfeitas, decorrentes da desigualdade social própria da organização capitalista. 


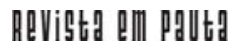

\} SERVIÇO SOCIAL E O TRABALHO COM FAMÍLIAS - HORST, C. H. M.; MIOTO, R. C. T. \}

DOI: $10.12957 /$ REP.2017.32749

O outro eixo diz respeito ao redimensionamento da ação profissional quanto ao seu alcance e direcionalidade. Ou seja, ao compreender as situações vivenciadas pelos indivíduos e suas famílias como expressões da "questão social", passa-se a sustentar que o enfrentamento delas, de fato, só se efetivará com a superação do modo de produção capitalista, com a transformação das bases de produção e reprodução das relações sociais. Nessa perspectiva, as ações profissionais devem ser pensadas na sua teleologia, incorporando-se o compromisso ético com a transformação social e ultrapassando-se, assim, os limites de sua eficiência operativa ou instrumental (GUERRA, 2000).

Ainda para Mioto (2015), o reconhecimento do terreno sóciohistórico sobre o qual se situa a profissão levou à adoção da categoria dos Direitos e da Cidadania como indicador central para o encaminhamento das ações dos assistentes sociais. Direitos devem ser entendidos como forma de concretização da cidadania por meio de políticas sociais pautadas no atendimento das necessidades humanas. Nessa postulação o Estado é considerado como a instância responsável pela garantia de direitos e pela oferta de atenção pública. No escopo dessa formulação, uma nova janela se abriu para o debate da família enquanto um dos sujeitos privilegiados de intervenção direta ou indireta dos assistentes sociais, considerando-se, por um lado, ser ela o lugar de materialização das expressões da questão social e, por outro, ser ela historicamente uma instância de provisão de bem-estar. Além disso, as ações profissionais para o enfrentamento das expressões da questão social no campo da política social se constroem para criar e articular "condições" de acesso concreto da população a melhores condições de vida. Ou seja, suas ações incidem diretamente no âmbito da proteção social.

Apesar de aberta tal janela e da publicação do livro Serviço Social e Família: a legitimação de uma ideologia, de Lídia M. Silva, no início dos anos de 1980, a sua exploração só começou, de fato, na segunda metade dos anos de 1990 e muito mais nos anos 2000, quando a família foi recolada explicitamente no plano da política social brasileira - especialmente da assistência social. A inclusão da matricialidade sociofamiliar foi um tanto quanto polêmica, uma vez que revelava uma clara contradição com a Constituição de 1988, que além das inovações que trouxe para a concepção de família, assumia a seguridade social como dever do Estado e, portanto, rompia com o caráter familista que sempre marcou a proteção social brasileira.

Os motivos da ausência do debate sobre família no arco da teoria social crítica pelo Serviço Social, especialmente nas décadas de 1970, 1980 e também de 1990 pode ser atribuído à preocupação com a consolidação dos fundamentos teórico-metodológicos da profissão, à inserção da profissão como interlocutor no debate das Ciências Sociais sobre política social e também a um possível alinhamento ao caminho adotado pela esquerda, de negação da família burguesa como objeto de interesse intelectual, como apontou Canevacci (1987). 


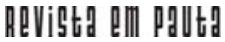

\} SERVIÇO SOCIAL E O TRABALHO COM FAMÍLIAS - HORST, C. H. M.; MIOTO, R. C. T. \}

DOI: $10.12957 /$ REP.2017.32749

É nesse contexto contraditório - em que se conjuga sinais do redesenho da política social brasileira e a forte presença de um corpo de conhecimento de viés estrutural funcionalista de natureza interdisciplinar para orientar o trabalho com famílias - que se começa investir na construção de novos marcos para o trabalho com famílias na esteira do projeto éticopolítico. Desde então, estes novos marcos têm se estruturado sobre uma concepção de família que implica no reconhecimento de sua multiplicidade de formas e de suas transformações históricas e também do lugar que lhe é atribuído nos sistemas de proteção social. Dessa forma, interessa pelas suas relações com o Estado (esferas legislativa, executiva e judiciária) e com o mercado, bem como a sua incorporação pela política social. Tem ganho expressão nesse processo os estudos referentes à centralidade da família no campo da reprodução social na sociedade capitalista, tanto na sua face de reprodução cotidiana da força de trabalho, aspecto apontado intensamente pelas autoras feministas de viés marxista, como no campo da reprodução ideológica, que sempre permeou as análises da profissão no pós-reconceituação.

Nas palavras de Mészáros (2002), trata-se de uma instituição que, ancorada na mediação de primeira ordem produtiva, constitui uma mediação de segunda ordem que "além do papel de reproduzir a espécie, participa de todas as relações reprodutivas do 'macrocosmo' social". Trata-se do papel decisivo atribuído à família na internalização e transmissão do sistema de valores da ordem social dominante. Consequentemente, a personalidade, e a individualidade humana, no processo de subjetivação, são determinadas por essas condições ontológicas. O que significa dizer, que os desenvolvimentos das capacidades humanas redundarão, sob a égide da lei do valor, em relações coisificadas, estranhadas. "[...] o lugar de todos os sentidos físicos e espirituais passou a ser ocupado, portanto, pelo simples estranhamento de todos esses sentidos pelo ter [...] (MARX, 2013). O que desmonta, de antemão, qualquer pretensão de idealizar essa instituição. Sua contradição se expressa exatamente no cenário conflituoso entre proteção e cuidado, e altos índices de violência e opressão, independente do arranjo familiar. Ao considerarmos o "momento predominante" dessa instituição na ordem burguesa é preciso apontar que há uma profunda contradição entre a nossa forma de organização da vida familiar e a possibilidade mais autêntica de desenvolvimento das nossas necessidades e potencialidades, inclusive no campo afetivo. Isso indica que essa forma de vivência não pode ser naturalizada como a única possível de organização familiar e por isso, a necessidade de superá-la sobre essas determinações. Pelo menos por dois motivos: 1) Pelo papel da família na reprodução da ordem burguesa, que tem como missão a transmissão e internalização dos valores dominantes pelos seus membros e para isso é necessário que a violência, a hierarquia e opressão (leia-se Machismo, Racismo e LGBTfobia etc.) sejam reproduzidas cotidianamente no seu interior; 2) Concretamente, ainda que as vivências entre os 


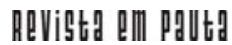

\} SERVIÇO SOCIAL E O TRABALHO COM FAMÍLIAS - HORST, C. H. M.; MIOTO, R. C. T. \}

DOI: $10.12957 /$ REP.2017.32749

sujeitos não reproduza somente a violência esperada de uma sociedade regida pela lei do valor, as famílias da classe trabalhadora, inseridas numa sociedade de classes, ordenada pela propriedade privada, não têm condições de garantir uma proteção aos seus.

Tal compreensão, tem contribuído para a construção de novos fundamentos para o trabalho com famílias em contraposição aos fundamentos postos pelo estrutural-funcionalismo. Situa-se a família no conjunto das relações sociais, desmistificando a clássica divisão entre esfera pública e privada, reafirmando o seu caráter histórico e as suas relações contraditórias. Busca-se desnaturalizar o trabalho desenvolvido na família e pela família, cuja naturalização permite os deslizamentos de responsabilidades, especialmente no campo do cuidado, dos serviços para as unidades familiares. Ademais, interpreta os processos familiares como expressões singulares arquitetadas nas famílias, que expressam as múltiplas relações que a condicionam e a definem. Nessa esteira, a dinâmica familiar não pode ser circunscrita ao âmbito das relações familiares, considerando os modelos de famílias pautados em funções e papéis. Com isso, abre-se uma ponte para o campo de debate sobre a direcionalidade do trabalho com famílias no campo da política social, postula-se ações orientadas pelas necessidades das famílias e não pelos problemas apresentados por elas - casos de família.

Esse deslocamento da lógica dos problemas - típica da perspectiva funcional-estruturalista - para a lógica das necessidades, permite pautar a perspectiva da defesa dos direitos sociais na sua universalidade, afastandose criticamente das propostas de focalização e mercantilização. Também permite desconstruir a ideia de família dissociada da condição de classe e de outros eixos de desigualdades, como gênero e raça. Isso rebate frontalmente na proposição do trabalho com famílias que se propõe a realizálo centralizado na abordagem das famílias e nas suas singularidades. Ao contrário, destaca-se o conjunto de ações que necessitam ser desenvolvidas para além das famílias, como sujeitos singulares.

Assim, nos anos 2000 o debate vai se estruturando e vai se instalando tensões nas concepções de família e nas formas de pensar e propor o trabalho com elas, embora ainda se observe a hegemonia dos cânones do conservadorismo, ancorado nos fundamentos teórico-metodológicos do estrutural-funcionalismo e de suas derivações.

Pesquisas realizadas com profissionais (SANTOS, 2010; CARRARO, 2011; TEIXEIRA, 2013) nos serviços sócio-assistenciais da política de assistência social indicam a forte presença de concepções de famílias pautadas num modelo ideal ou de forte tendência da preservação dos papéis idealizados de pai e mãe, além de ausência de conexões entre as questões familiares e a estrutura social. Romano (2009) afirma que, dentre as respostas dos seus sujeitos de pesquisa, destacaram-se as que atribuem aos próprios usuários a resolução pelos problemas vivenciados. As análises de conjuntura 


\section{ReVistg all paltg}

\} SERVIÇO SOCIAL E O TRABALHO COM FAMÍLIAS - HORST, C. H. M.; MIOTO, R. C. T. \}

DOI: $10.12957 /$ REP.2017.32749

referentes ao contexto social mais amplo de inserção desse indivíduo e/ou família em determinada classe social, praticamente inexistem na fala dos profissionais.

Campos (2010), por meio de sua análise, demonstra que o trabalho social com famílias tem implicado a ausência de metodologias claras e uma "miscelânia" de correntes teóricas, além da falta de comunicação e articulação com a rede de serviços. Nessa mesma direção, Abrão (2012, p. 94), referindo-se às assistentes sociais, afirma que "ainda persiste o trabalho que reproduz e mantém os referenciais teóricos conservadores e uma prática imediatista".

No âmbito da política de saúde, as pesquisas de Alves (2010), Barcelos (2011) e Caetano (2010) demonstram que os profissionais tendem a agir a partir de códigos culturais hegemônicos que atribuem e naturalizam o papel da família, especialmente, para incorporá-la ao processo de cuidado. A família, em princípio, é tomada como a grande responsável pelo cuidado de seus doentes, independentemente das condições socioeconômicas nas quais se encontra. Simão (2015), num estudo sobre o trabalho de cuidado à pessoa dependente vinculada ao Programa Melhor em Casa, por meio de entrevistas com famílias em suas residências, relata situações em que, apesar das precárias condições para cuidar, as famílias são enquadradas no Programa pelos profissionais dos serviços de saúde e responsabilizadas pelo cuidado, inclusive legalmente.

Cabe destacar que a persistência dessa perspectiva pautada numa cultura disciplinar se apresenta também nas próprias formulações das políticas sociais. Mioto (2015), ao analisar os documentos orientadores da política de assistência social, indica as contradições e as ambiguidades presentes nesses documentos, especialmente relacionadas à concepção de matricialidade sociofamiliar e aos procedimentos a serem adotados com as famílias. Afirma que esses documentos favorecem, no cotidiano dos serviços socioassistenciais, interpretações a partir de construtos já consolidados em práticas tradicionais da assistência social.

A nosso ver, os exemplos de pesquisas recentes, apontadas até aqui, demarcam a necessidade histórica de uma atuação junto à famílias que fortaleça a luta de ruptura com o conservadorismo. Acreditamos, conforme apontou Silva (1982, p.82), que ainda "sob a capa de uma aparente heterogeneidade, existe uma certa unidade na forma de conceber a família", logo na forma de pensar metodologias de trabalho junto a famílias. Resumindo, na dialética entre passado e presente, continuamos assistindo no trabalho com famílias:

- a uma reatualização do conservadorismo, na responsabilização da família pelos cuidados, e, com isso, no reforço do papel da mulher pela "falha" nos cuidados, na proteção e na socialização, o que acaba reforçando papeis socialmente construídos. Trata-se 
da busca pelo retorno dos papeis típicos da família nuclear patriarcal, constituída por pai, mãe, ambos heterossexuais, e seus filhos (CARDOSO; TEIXEIRA, 2014; MIOTO et al; 2015; JORGE, 2009);

- à psicologização da realidade das famílias, focalizando nas características psicológicas para resgatar e fortalecer os vínculos familiares, em detrimento do entendimento da realidade de negligência que essas famílias sofrem por parte do Estado (CARDOSO; TEIXEIRA, 2014; HORST; AZEVEDO, 2013; MIOTO et al., 2015; JORGE, 2009; SILVEIRA JÚNIOR, 2016);

Diante disso, fica muito clara a tendência atual de direcionar o trabalho com famílias na sua instrumentalidade funcional, reiterando o movimento hegemônico da sociedade, com base numa produção bibliográfica de cunho estrutural-funcionalista e também nas ambiguidades contidas na orientação das próprias políticas setoriais em relação à família, o que significa velhas práticas travestidas em novos discursos. Assim, a reiteração de um processo interventivo na lógica do disciplinamento, da responsabilização e da culpabilização das famílias flui como um continuum naturalizado e necessário, embalado pela ideia do protagonismo das famílias. Nesse contexto, a ausência ou a incipiência de resultados efetivos relacionados à intervenção profissional com famílias tem sido atribuída, ora como culpa do Estado, que não garante os direitos, ou da família, que, apesar de todas as informações sobre seus direitos, não é competente o suficiente para acessar o que lhe é de direito, ou ainda, para efetuar mobilizações para reivindicar tais direitos (MIOTO, 2017).

Nesse contexto, torna-se imprescindível o aprofundamento do diálogo sobre a família dentro da tradição marxista, compreendendo-a a partir da sua contraditoriedade e particularidade no capitalismo e apostando nessa contribuição para a construção de novos valores éticos, centrados efetivamente na liberdade e na justiça social - parâmetros que sustentam nosso código de ética e constitui nosso projeto profissional crítico - no trabalho cotidiano com as famílias. Ou seja, construir respostas concretas que vão para além das determinações da política social, das cartilhas e indicações governamentais.

A busca de práticas mediadas pelo projeto profissional não está apenas no domínio do pensamento. Trata-se de identificar na realidade e definir/ priorizar/realizar estratégias e ações e atividades que se impõem e que são essenciais e indispensáveis, não só ao acesso às políticas sociais como direito do cidadão e dever do Estado, mas também aos processos de formação, mobilização e organização das massas trabalhadoras, tendo em vista sua participação no controle social dos serviços prestados e na imposição de limites ao capital [...] (VASCONCELOS, 2015, p.432). 


\section{ReVistg all paltg}

\} SERVIÇO SOCIAL E O TRABALHO COM FAMÍLIAS - HORST, C. H. M.; MIOTO, R. C. T. \}

DOI: $10.12957 /$ REP.2017.32749

Nosso entendimento compreende o trabalho com famílias como um lócus privilegiado de reflexão e provocações, a partir da realidade concreta dos sujeitos atendidos por nós, que pode contribuir nos processos de desmistificação da sociabilidade do capital. Afinal, "o processo de construção e consolidação de práticas mediadas pelo projeto profissional exige, de partida, análise concreta de situações concretas" (VASCONCELOS, 2015, p. 448 - grifos originais).

\section{Concluindo, desafios do caminho...}

Apontamos, ao longo do texto, a relação contraditória entre política social no capitalismo dependente e a centralidade das famílias, bem como alguns traços que constituem o trabalho com famílias ao longo da história do Serviço Social brasileiro. O percurso traçado buscou explorar as contradições no sentido de "evidenciá-las e fazer delas potencialidades de luta e não encobri-las com pactos de sujeição" (BOSCHETTI, 2016, p.13).

O Projeto Ético Político exige, cada vez mais, assistentes sociais com uma formação continuada, crítica e direcionada pelo fim da exploração de classes. Nesse sentido, torna-se necessário aprofundar os estudos de cariz marxista e desenvolver investigações que demonstrem como se implicam os processos de regulação da vida familiar e os processos de articulação e delegação de responsabilidades às famílias, objetivando construir intervenções que possam se contrapor ou resistir à lógica dominante. Ou seja, é necessário tornar cada vez mais compreensível a articulação entre as diferentes esferas do Estado para a efetivação dos processos de responsabilização e culpabilização das famílias na qual os assistentes sociais estão implicados.

É no cotidiano profissional que esse desafio se coloca como emergente. A não compreensão das particularidades da política social no continente latino-americano implica um trabalho com famílias que desconsidera as particularidades desses sujeitos, correndo o risco de limitar as reflexões a melhorias imediatas, o que serve apenas para controlar a pobreza e legitimar o Estado capitalista. Nesse sentido, "o projeto neoconservador valendo-se de novas roupagens, fragmentará cada vez mais as análises e ações do profissional" (YAZBEK, 2016, p. 11). É preciso entender as demandas colocadas pelos usuários dos serviços sociais e suas famílias como expressões da luta de classes, buscando romper com uma visão "a-histórica do indivíduo abstraído, artificialmente, da produção material, das relações de classe, enfim, da sociedade" (IAMAMOTO; CARVALHO, 2014, p. 82).

Ao pensarmos que a força de trabalho é superexplorada ${ }^{3}$ MARINI, 2011), e, ao mesmo tempo que as famílias não acessam um sistema de pro-

3 “[...] a superexploração é melhor definida pela maior exploração da força física do trabalhador, em contraposição à exploração resultante do aumento de sua produtividade, e tende normalmente a se expressar no fato de que a força de trabalho se remunera abaixo do seu valor real" (MARINI, 2011, p. 180). 


\section{ReVistg all paltg}

S SERVIÇO SOCIAL E O TRABALHO COM FAMÍLIAS - HORST, C. H. M.; MIOTO, R. C. T. \}

DOI: $10.12957 /$ REP.2017.32749

teção social público e universal, elas são, consequentemente, sobre-carregadas com funções que não são capazes de arcar. Nem de longe trata-se de famílias que não se responsabilizam pelos seus membros; pelo contrário, as famílias da classe trabalhadora vêm sendo historicamente sobrecarregadas. Conforme apontam Paiva, Carraro e Rocha (2014, p.41), reconhecer a importância das famílias

[...] não é pretexto para sua supervalorização, ou entificação, ou seja, sua pseudoafirmação como sujeito, vez que efetivamente isso é uma impossibilidade. Tal percurso equívoco, além de encobrir as contradições do processo de pauperização, tem submetido as famílias, sujeitos de direitos da assistência social, a uma solitária e contraditória condição de protagonista social, cuja proteção de seus membros deve ser assegurada, sob auspícios dos serviços socioassistenciais. Mas não só proteção, sobretudo, cabe a esse fantasmático ente a tarefa de sair da pobreza.

Retomando o sentido da epígrafe que abre o presente texto, nossa intenção é destacar a necessidade de construir e caminhar junto com as famílias da classe trabalhadora. Ou seja, defender um exercício profissional com famílias que não se resuma em responsabilização e/ou no apassivamento delas, mas, ao contrário, que construa junto às famílias outras perspectivas e apostas. 


\section{Referências}

ABRÃO, K. C. O trabalho dos assistentes sociais com famílias no contexto da Política Nacional de Assistência Social em Goiânia. Dissertação (Mestrado). Pontifícia Universidade Católica de Goiás. Goiania: PUCGO. 2012, $143 \mathrm{f}$.

ALVES, F. L. Trajetórias de acesso da população aos serviços do SUS: um estudo sobre a cirurgia bariátrica. 2010. 165 f. Dissertação de Mestrado, Programa de Pós-Graduação em Serviço Social, UFSC, Florianópolis.

BARCELOS, M. S. A incorporação da família nos serviços de saúde: um debate a partir das concepções dos profissionais num hospital de alta complexidade. Dissertação de Mestrado, Programa de Pós-Graduação em Serviço Social, UFSC, Florianópolis, 2011.

BATTHYÁNY, D. K. Las políticas y el cuidado em America Latina: una mirada a las expectativas regionales. Santiago: CEPAL - Série Assuntos de Gênero, n. 124, 2015.

BOSCHETTI, I. Tensões e possibilidades da política de assistência social em contexto de crise do capital. Argumentum, v.8, n.2, 2016.

CAETANO, P. S. Família e Política Social: um estudo sobre o acompanhante nos serviços de saúde de alta complexidade. Trabalho de Conclusão de Curso. (Graduação em Serviço Social) - Universidade Federal de Santa Catarina. 2010.

CAMPOS, L. G. O trabalho com famílias na proteção social especial de média complexidade no município de Londrina/PR. Dissertação de Mestrado. Programa de Pós Graduação em Política Social. UEL. Londrina, 2010, 132 f. CAMPOS, M. S. O Casamento da política social com a família: feliz ou infeliz? In: MIOTO, R. C. T; CAMPOS, M. S; CARLOTO, C. M. (orgs.) Familismo, Direitos e Cidadania. Contradições da política social. São Paulo, Cortez, 2015.

CANEVACCI, M. Dialética da Família: Gênese de uma instituição repressiva. São Paulo: Editora Brasiliense. 5 ed. 1987.

CARDOSO, J. N; TEIXEIRA, S. M. Política de assistência social e o trabalho social com família: autonomia ou maternagem? Serviço Social em Revista, Londrina, v.17, n.1, p.66-87, jul/dez. 2014.

CARRARO, G. As pesquisas avaliativas de políticas sociais públicas: um estudo sobre a metodologia do trabalho com famílias no SUAS. Dissertação (MESTRADO). Programa de Pós-Graduação em Serviço Social. Pontifícia Universidade Católica do Rio Grande do Sul. 2011, $226 f$. 


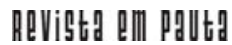

\} SERVIÇO SOCIAL E O TRABALHO COM FAMÍLIAS - HORST, C. H. M.; MIOTO, R. C. T. \}

DOI: $10.12957 /$ REP.2017.32749

COSTA, A. P. M; GOLDANI, J. M. A influência do Contexto Familiar nas decisões Judiciais a Respeito de Atos Infracionais de Adolescentes: o intervencionismo familiar ainda se faz presente? Textos \& Contextos (Porto Alegre), v.14, n.1, p. 87-103, jan/jun, 2015.

GOLDANI, A. M. Reinventar políticas para as famílias reinventadas: entre la "realidad" brasileña y la utopia. Lineamientos de acción y propuestas de políticas hacia las famílias. Serie Seminarios y Conferencias, Chile, n. 46, CEPAL, p.319-345, 2005. Disponível em: <http://www.pasa.cl/wp-content/ uploads/2011/08/Reinverntar_politicas_para_familias_reinventadas _Goldani_Ana_Maria.pdf>. Acesso em: 12 fev. 2014.

GUERRA, Y. A instrumentalidade no trabalho do assistente social. Cadernos de Capacitação em Serviço Social e Política Social, módulo 4. Brasília: UnB. 2000.

HORST, C. H. M; AZEVEDO, A. S. M. Família, afinal o que é? Um estudo dos trabalhos do serviço social no ENPESS. Monografia, Departamento Serviço Social, UFES. 2013.

IAMAMOTO, M. V; CARVALHO, R. Relações Sociais e Serviço Social no Brasil: esboço de uma interpretação histórico-metodológica. São Paulo: Cortez; Lima: CELATS, 1982.

IAMAMOTO, M. V. A questão social no capitalismo. In: Revista Temporalis. Ano. 2, n.3. Brasília: ABEPSS, 2001.

. Renovação e Conservadorismo no Serviço Social. Ensaios Críticos. 12. Ed. São Paulo. Cortez, 2013.

- Relações sociais e serviço social no Brasil: esboço de uma interpretação histórico-metodológica. 41 ed. São Paulo, Cortez, 2014.

JORGE, C. F. A construção teórica das relações entre família e serviço social brasileiro no contexto dos diferentes projetos societários. Dissertação de Mestrado. Programa de Pós Graduação em Serviço Social. PUC-SP, 2009.

MARINI, R. M. Ruy Mauro Marini — Vida e obra. TRASPADINI, R; STEDILE, J. P. (orgs.) 2.ed. São Paulo. Expressão Popular. 2011.

MARQUES, R. M. O lugar das políticas sociais no capitalismo contemporâneo. In: Argumentum, Vitória (ES), v.7, n. 2, p. 7-21, jul./dez. 2015.

MARX, K. O capital: crítica da economia política. Livro 1. São Paulo: Boitempo, 2013.

MÉSZÁROS, I. Para Além do Capital. Rumo a uma teoria da transição. Boitempo. 2002.

MIOTO, R. C. Serviço Social e Intervenção Profissional com Famílias: o debate brasileiro em pauta. In CARVALHO, M. I. (ORG) Família e Serviço Social. Lisboa: Pactor. 2015. 


\section{ReVistg ell paUtg}

\} SERVICCO SOCIAL E O TRABALHO COM FAMÍLIAS - HORST, C. H. M.; MIOTO, R. C. T.

DOI: $10.12957 /$ REP.2017.32749

Família e Proteção Social: Intervenções profissionais contemporâneas? (No prelo). 2017.

MIOTO, R. C. et. al. (orgs.) Familismo, Direitos e Cidadania. Contradições da política social. São Paulo, Cortez, 2015.

MOTA, A. E. A regressão civilizatória e as expropriações de direitos e das políticas sociais. Argumentum, Vitória, v. 9, n. 3, p. 30-36, set./dez. 2017.

NEDER, G. Ajustando o foco das lentes: um novo olhar sobre a organização das famílias no Brasil. In KALOSTIAN, S. M. (ORG) Família Brasileira: a base de tudo. São Paulo: Cortez, 1994.

PAIVA, B. A; OURIQUES, N. O. Uma perspectiva latinoamericana para as políticas sociais: quão distante está o horizonte? Katálysis v. 9 n. 2 jul./dez. 2006.

. (org.) Sistema Único de Assistência Social em perspectiva: direitos, políticas públicas e superexploração. São Paulo, Veras Editora, 2014.

PAIVA, B. A; ROCHA, M; CARRARO, D. Política social na América Latina: ensaio de interpretação a partir da Teoria Marxista da Dependência. Ser Social, Brasília, v.12, n.26, p. 147-175, jan/jun, 2010.

RICHMOND, M. E. Caso social individual. Buenos Aires: Humanitas, 1977.

RODRIGUES, M. O exercício profissional 30 anos depois do Congresso da Virada. Revista Praia Vermelha, Rio de Janeiro, v. 21, no2, p. 51-68, Jan-Jul, 2012.

ROMANO, A. P. H. Entre socialização da informação e a organização coletiva: a dimensão socioeducativa na atuação com grupos nos CRAS em São José do Rio Preto/SP. Dissertação (MESTRADO). Franca: UNESP, 2009, $238 \mathrm{f}$.

SANTOS, R. O desafio do trabalho com famílias na política de assistência social no Vale do Paraíba. Dissertação (Mestrado) - Programa de Pósgraduação em Serviço Social, Pontifícia Universidade Católica de São Paulo, São Paulo. PUCSP- São Paulo 2010, 127p.

SILVA, L. M. M. R. Serviço Social e Família: a legitimação de uma ideologia. 2. Ed. São Paulo, Cortez, 1982.

SILVEIRA JUNIOR, A. A. A assistência social e as ideologias do social-liberalismo: tendências político-pedagógicas para a formação dos trabalhadores do SUAS. Tese (Doutorado em Serviço Social) - Universidade Federal de Pernambuco. 2016.

SIMÃO, V. M. O trabalho de cuidado social. Relatório Final de Pós-Doutorado: UCPEL/CAPES. 2015.

SIMIONATTO, I. As expressões ideoculturais da crise capitalista da atualidade. Cadernos de Capacitação em Serviço Social e Políticas Sociais, módulo 01. Brasília: UnB. 1999. 


\section{ReVistg all paltg}

ISERVICO SOCIAL E O TRABALHO COM FAMÍLIAS - HORST, C. H. M.; MIOTO, R. C. T. \}

DOI: 10.12957/REP.2017.32749

TEIXEIRA, S. M. A Família na política de Assistência Social: concepções e as tendências do trabalho social com família nos CRAS de Teresina - PI. Teresina: EDUFPI, 2013. 218 p.

VASCONCELOS, A. M. A/O Assistente Social na Luta de Classes - Projeto Profissional e Mediações Teórico-Práticas. 1.ed. São Paulo: Cortez, 2015.

YAZBEK, M. C. Os fundamentos do Serviço Social na contemporaneidade. Cadernos Capacitação em Serviço Social e política social, módulo. 04. Brasília: UNB. 1999.

. O desafio da defesa das Políticas Públicas para o Serviço Social. Argumentum, Vitória (ES), v.8, n.1, p. 6-13, jan./abr. 2016.

DOI: 10.12957/rep.2017.32749

Recebido em 29 de agosto de 2017.

Aprovado para publicação em 04 de fevereiro de 2018.

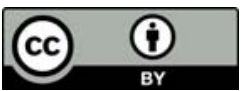

A Revista Em Pauta: Teoria Social e Realidade Contemporânea está licenciada com uma Licença Creative Commons Atribuição 4.0 Internacional. 